\title{
リン酸塩緩衙溶液中におけるアセトグアナミンのホルムアルデヒド によるヒドロキシメチル化*
}

\author{
佐藤 謙二*1 $・$ 阿部 芳首*1
}

(受付 1975 年 12 月 15 日・審査終了 1976 年 2 月 5 日)

\footnotetext{
要 旨 アセトグアナミン (AGH) のホルムアルデヒドによる初期ヒドロキシメチル化について， リン酸水素ニナトリウムー水酸化ナトリウム緩衝溶液中で $\mathrm{pH} 11 \sim 12$ において検討を加えた。この 結果, 一般塩基触媒反応であることが分かったので，主反応は (1), (2) 式のよ5に進行し，かっ (1) 式の反応が律速段階と考えられる。ここで $\mathrm{A}^{-}$は塩基触媒, HA はこの共役酸を示す.

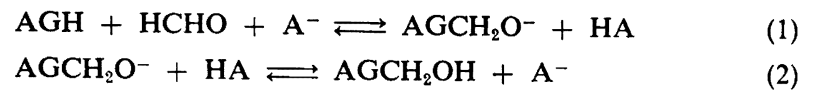

\section{1 緒言}

塩基性領域に拊るるセトグアナミン (AGH) のホル ムアルデヒド $(\mathrm{F})$ によるヒドロキシメチル化の速度論に ついては, 森本 ${ }^{1)}$ は $\mathrm{pH} 8$ 付近の場合について, 浦上ら ${ }^{2)}$ は $\mathrm{pH} 11$ 以下について, その後, 佐藤ら ${ }^{3)}$ は中性から水 酸化ナトリウム濃度約 $1.2 \mathrm{~mol} / l$ の強塩基性領域まで検 討している.

本報では，塩基性における初期ヒドロキシメチル化機 構を究明するため, リン酸水素二ナトリウム一水酸化ナ トリウム緩衝溶液を用い $\mathrm{pH} 11 \sim 12$ において検討を加 えた。

AGH のFによるとドロキシメチル化におけるモノメ チロール AGH $\left(\mathrm{AGCH}_{2} \mathrm{OH}\right)$ の生成を次式に示した.

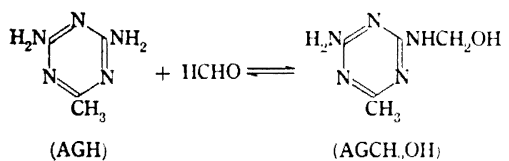

以下, [ ], [ ] 法それぞれ濃度 $(\mathrm{mol} / l)$, 初濃度 $(\mathrm{mol} / l)$ を示した.

\section{2 実験}

\section{1 試蒌および試料}

$\mathrm{AGH}$ は市販品を水から再結晶して用いた，Fは前 報4)と同様な操作で精製した。無水リン酸水素二ナトリ ウム, 水酸化ナトリウム, 塩化カリウム, 亜硫酸ナトリ

*本報を「メラミン樹脂に関する研究第13報」とす る

*1 東京理科大学理工学部工業化学科（亚278 野田市山 崎東山 2641)
ウム法に用いた試薬は市販特級品を用いた.

\section{2 反応速度の測定法}

$0^{\circ} \mathrm{C}$ (反応温度) に調整した恒温槽中において，一定量 の $\mathrm{AGH}$, 水酸化ナトリウム, 無水リン酸水素二ナトリ ウム, さらにイオン強度を一定にするための塩化カリウ ムを蒸留水を用いて $500 \mathrm{~m} l$ に溶解し, 別に一定濃度の $\mathrm{F}$ 水溶液 $500 \mathrm{~m} l$ を調製し, 両液を混合した. $\mathrm{F}$ 消費量 は亜硫酸ナトリウム法, $\mathrm{pH}$ はガラス電極 $\mathrm{pH}$ メーター を用いて測定した。 $\mathrm{pH}$ 測定に際し空気中の炭酸ガスの 影響を考虑し窒素気流中で測定した. Table 1 に反応条 件をまとめた。

\section{3 実験結果および考察}

\section{$3.1 k$ の算出}

初速度 $R_{0}$ は消費 $\mathrm{F}$ と反応時間のプロットの初期こ 5配から求め, Fig. 1 にその数例を示した。

$[\mathrm{AGH}]_{0}$ 拈よび [水酸化ナトリウム $]_{0}$ を一定にし, $[\mathrm{F}]_{0}$ を変えて実験を行い, Fig. $2 に \log R_{0}$ と $\log [\mathrm{F}]_{0}$ の

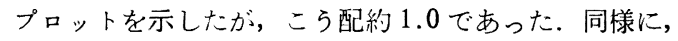
$[\mathrm{F}]_{0} お$ おび[水酸化ナトリウム $]_{0}$ を一定にして $[\mathrm{AGH}]_{0}$ を变えて実験を行い, Fig. 2 に $\log R_{0}$ と $\log [\mathrm{AGH}]_{0}$

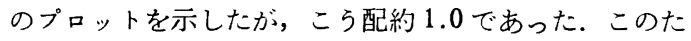
め, $k$ を二次速度定数とすると $R_{0}=k[\mathrm{AGH}]_{0}[\mathrm{~F}]_{0}$ の 速度式が成立する。

この速度式を用いて $k$ を算出し，Table 1 に示した。

\section{$3.2 k_{\mathrm{A}^{-}}, k_{\mathrm{HA}}$ の算出}

リン酸水素二ナトリウム一水酸化ナトリウム緩衝溶 液らでは (1) 式に示した平衡が成立し、リン酸イオン $\left(\mathrm{PO}_{4}{ }^{3-}\right)$ を生成する.

$$
\begin{aligned}
& \mathrm{HPO}_{4}{ }^{2-}+\mathrm{OH}^{-} \stackrel{K_{1}}{\rightleftarrows} \mathrm{PO}_{4}{ }^{3-}+\mathrm{H}_{2} \mathrm{O} \\
& \text { ( } K_{1} \text { : 平衡定数) }
\end{aligned}
$$


Table 1. Reaction conditions and the rate constants $k$ for the hydroxymethylation of acetoguanamine in phosphate buffers at $0^{\circ} \mathrm{C}$ and ionic strength of 0.56 .

\begin{tabular}{rcccccc}
\hline \hline \multirow{2}{*}{$\begin{array}{c}\text { Expt1 } \\
\text { No. }\end{array}$} & $\begin{array}{c}c \\
{\left[\mathrm{Na}_{2} \mathrm{HPO}_{4}\right]} \\
(\mathrm{mol} / l)\end{array}$ & $\begin{array}{c}\text { Added } \\
{[\mathrm{NaOH}]} \\
(\mathrm{mol} / l)\end{array}$ & $\mathrm{pH}$ & $\begin{array}{c}R_{0} \\
(\mathrm{~mol} / l \mathrm{~min})\end{array}$ & $\begin{array}{c}k \\
(l / \mathrm{mol} \mathrm{min})\end{array}$ & $\begin{array}{c}k^{\prime} \\
(l / \mathrm{mol} \mathrm{min})\end{array}$ \\
\hline 1 & 0.150 & 0.036 & 11.2 & $3.50 \times 10^{-5}$ & $9.52 \times 10^{-2}$ & $3.70 \times 10^{-2}$ \\
2 & 0.100 & 0.024 & 11.2 & $3.01 \times 10^{-5}$ & $8.05 \times 10^{-2}$ & \\
3 & 0.075 & 0.018 & 11.2 & $2.39 \times 10^{-5}$ & $6.17 \times 10^{-2}$ & \\
4 & 0.050 & 0.012 & 11.2 & $2.19 \times 10^{-5}$ & $5.72 \times 10^{-2}$ & \\
\hline 5 & 0.150 & 0.045 & 11.4 & $4.88 \times 10^{-5}$ & $1.25 \times 10^{-1}$ & \\
6 & 0.120 & 0.036 & 11.4 & $4.01 \times 10^{-5}$ & $1.02 \times 10^{-1}$ & $4.49 \times 10^{-2}$ \\
7 & 0.050 & 0.015 & 11.4 & $3.09 \times 10^{-5}$ & $7.35 \times 10^{-2}$ & \\
\hline 8 & 0.150 & 0.065 & 11.9 & $9.80 \times 10^{-5}$ & $2.52 \times 10^{-1}$ & \\
9 & 0.120 & 0.052 & 11.9 & $8.51 \times 10^{-5}$ & $2.16 \times 10^{-1}$ & $7.60 \times 10^{-2}$ \\
10 & 0.075 & 0.033 & 11.9 & $5.01 \times 10^{-5}$ & $1.39 \times 10^{-1}$ & \\
\hline 11 & 0.150 & 0.090 & 12.2 & $1.30 \times 10^{-4}$ & $3.38 \times 10^{-1}$ & \\
12 & 0.120 & 0.072 & 12.2 & $1.18 \times 10^{-4}$ & $2.99 \times 10^{-1}$ & $1.19 \times 10^{-1}$ \\
13 & 0.050 & 0.030 & 12.2 & $7.09 \times 10^{-5}$ & $1.75 \times 10^{-1}$ & \\
\hline
\end{tabular}

a) $[\mathrm{AGH}]_{0}, 0.01 \mathrm{~mol} / l ;[\mathrm{F}]_{0}, 0.04 \mathrm{~mol} / l$

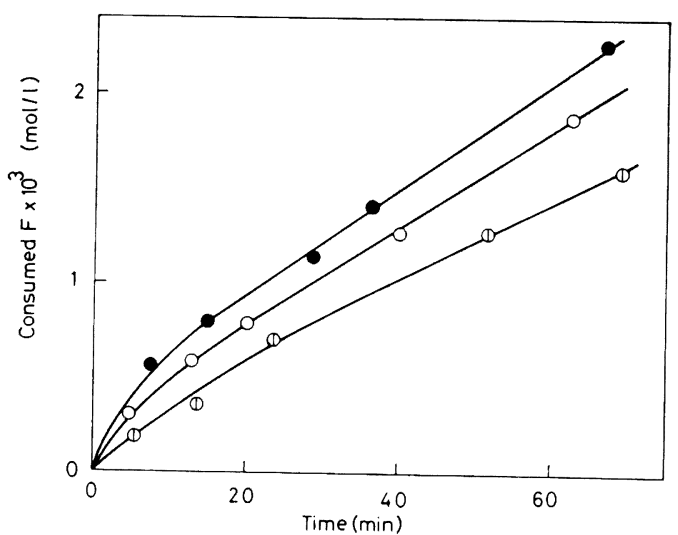

Fig. 1. Consumed $F$ vs, reaction time for the hydroxymethylation of acetoguanamine in phosphate buffers. 10 .

- No. 8 in Table 1; O, No. 9; (D. No.

リン酸水素イオン $\left(\mathrm{HPO}_{4}{ }^{2-}\right)$ の酸解離定数を $K_{\mathrm{A}}$ とす ると， $K_{1}=K_{\mathrm{A}} / K_{\mathrm{W}}$ で与えられるので， $K_{\mathrm{A}}=2 \times 10^{-12}$ $\left(18^{\circ} \mathrm{C}\right)^{8)}, \mathrm{p} K_{\mathrm{W}}=14.3\left(18^{\circ} \mathrm{C}\right)^{7)}$ の值を代入すると， $K_{1}=$ $4 \times 10^{2}$ になる $\left(K_{\mathrm{A}}\right.$ の值として，このほかに $K_{\mathrm{A}}=3.6 \times$ $10^{-13}\left(18^{\circ} \mathrm{C}\right)^{8)}$ の值が知られている).この $K_{1}$ の值を用 いて, Table 1 に示した仕込み条件における $\left[\mathrm{HPO}_{4}{ }^{2-}\right]$, $\left[\mathrm{PO}_{4}{ }^{3-}\right]$ を算出した. この結果, Table 1 の No. 1〜4,

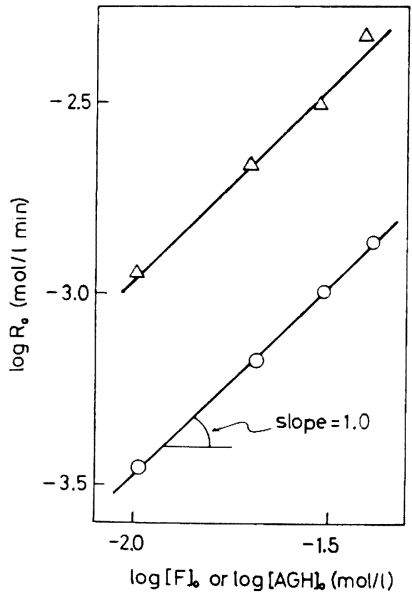

Fig. 2. $\log R_{0}$ vs. $\log [\mathrm{F}]_{0}$ or $\log [\mathrm{AGH}]_{0}$ in unbuffered solutions at $5^{\circ} \mathrm{C}$.

$\bigcirc, \log R_{0}$ vs. $\log [\mathrm{F}]_{0}\left[[\mathrm{NaOH}]_{0}, 0.2 \mathrm{~mol} / l\right.$; $[\mathrm{AGH}]_{0}, 0.01 \mathrm{~mol} / l ;[\mathrm{F}]_{0} /[\mathrm{AGH}]_{0}=1.0,2.0$, $3.0,4.0] ; \triangle, \log R_{0} v s . \log [\mathrm{AGH}]_{0}\left[[\mathrm{NaOH}]_{0}\right.$, $0.2 \mathrm{~mol} / l ;[\mathrm{F}]_{0}, 0.04 \mathrm{~mol} / l ;[\mathrm{AGH}]_{0} /[\mathrm{F}]_{0}=1.0$, $2.0,3.0,4.0]$.

$5 \sim 7,8 \sim 10,11 \sim 13$ において, $\left[\mathrm{HPO}_{4}{ }^{2-}\right] /\left[\mathrm{PO}_{4}{ }^{3-}\right]=r$ はそれぞれ 3.2，2.3，1.3，0.7 の一定值を示す.

Bell ら ${ }^{8)}$ はアセトンのヨウ素化において， $k$ は (2) 式 で与えられると述べている，ここで，HA は非解離の

高分子論文集, Vol. 33, No. 5 (1976) 


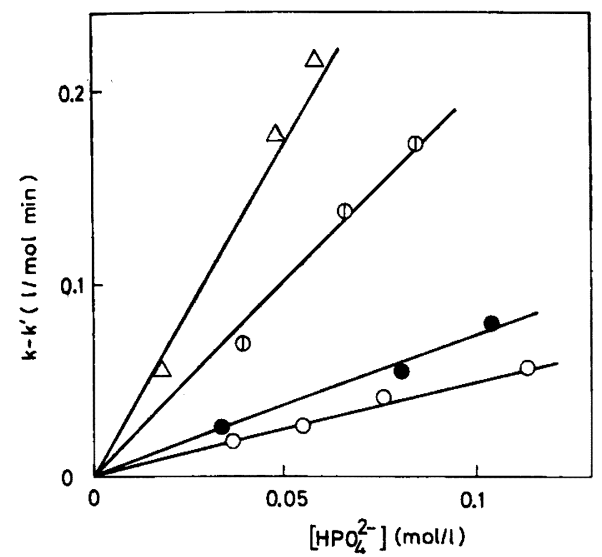

Fig. 3. $k-k^{\prime} v s$. [ $\left.\mathrm{HPO}_{4}{ }^{2-}\right]$ at constant $r$ : Demonstration of general base catalysis for the hydroxymethylation of acetoguanamine. O, $r=3.2$ (No. 1-4 in Table 1); $\bullet, r=$ 2.3 (No. 5-7); (1), $r=1.3$ (No. 8-10); $\Delta, r$ $=0.7$ (No. 11-13).

酸, $\mathrm{A}^{-}$はこの共役塩基であり, $k_{\mathrm{H}_{2} \mathrm{O}}, k_{\mathrm{OH}^{-}}, k_{\mathrm{H}^{+}}, k_{\mathrm{A}^{-}}$, $k_{\mathrm{HA}}, k_{\mathrm{P}}$ はそれぞれの触媒定数である. 本報では $\mathrm{HA}$ は $\mathrm{HPO}_{4}{ }^{2-}, \mathrm{A}^{-}$は $\mathrm{PO}_{4}{ }^{3-}$ に相当する.

(2) 式に (4) 式に示した $k^{\prime}$ を代入すると（3) 式が得 られる. (3) 式において [HA]/[A-]=r なので (5) 式に 変形でき，(7) 式に示したパラメーター $\alpha$ を適用するこ とにより (6) 式に導かれる.

$$
\begin{aligned}
& k=k_{0}\left(=k_{\mathrm{B}_{2} \mathrm{O}}\left[\mathrm{H}_{2} \mathrm{O}\right]\right)+k_{\mathrm{OH}^{-}}\left[\mathrm{OH}^{-}\right]+k_{\mathrm{H}^{+}}\left[\mathrm{H}^{+}\right] \\
&++k_{\mathrm{A}^{-}}\left[\mathrm{A}^{-}\right]+k_{\mathrm{HA}}[\mathrm{HA}]+k_{\mathrm{P}}[\mathrm{HA}]\left[\mathrm{A}^{-}\right] \\
&=k^{\prime}+k_{\mathrm{A}^{-}-}\left[\mathrm{A}^{-}\right]+k_{\mathrm{HA}}[\mathrm{HA}]+k_{\mathrm{P}}[\mathrm{HA}]\left[\mathrm{A}^{-}\right] \\
& k^{\prime}=k_{0}++k_{\mathrm{OH}^{-}}-\left[\mathrm{OH}^{-}\right]+k_{\mathrm{H}^{+}}\left[\mathrm{H}^{+}\right] \\
& k-k^{\prime}=\left(\frac{k_{\mathrm{A}^{-}}}{r}+k_{\mathrm{HA}}+k_{\mathrm{P}}\left[\mathrm{A}^{-}\right]\right)[\mathrm{HA}] \\
&= \alpha[\mathrm{HA}] \\
& \alpha= \frac{k_{\mathrm{A}}^{-}}{r}+k_{\mathrm{HA}}+k_{\mathrm{P}}\left[\mathrm{A}^{-}\right]
\end{aligned}
$$

Fig. $3 に k-k^{\prime}$ と $\left[\mathrm{HPO}_{4}{ }^{2-}\right]$ のプロットを示した. ここで $k^{\prime}$ は (4) 式から分かるよ5に非緩衝溶液の場合 の $k$ であり, 塩基触媒として水酸化ナトリウムを用い て得た $k^{\prime}$ の值を Table 1 に示した。 もしも $k_{\mathrm{P}}$ があ る值を持つならば, Fig. 3 のプロットのこう配は (7) 式 の $\alpha$ なので, このプロットは上方に凹な曲線になるはず であるが，Fig. 3 から分かるよ5に，ほほ直線関係が成 立することから， $k_{\mathrm{P}} \doteqdot 0$ と考えられる。この直線のこう 配から， $r=0.7,1.3,2.3,3.2$ における $\alpha$ はとれぞれ $3.40,1.98,0.73,0.51 l^{2} / \mathrm{mol}^{2} \mathrm{~min}$ の值が得られた。

上記の $\alpha$ の値を用い, Fig. 4 に $\alpha$ と $1 / r$ の関保を 示した。 この直線のこう配から $k_{\mathbf{A}^{-}}$を求めると $k_{\mathrm{A}^{-}}=$

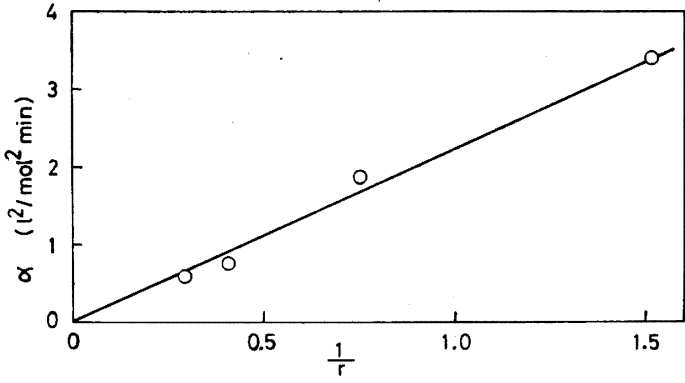

Fig. 4. Relationship between $\alpha$ and $1 / r$.

$2.25 l^{2} / \mathrm{mol}^{2} \min$ になることが分かった。 また， $1 / r=0$ における $\alpha$ から $k_{\mathrm{HA}}$ を求めると, $\mathrm{HPO}_{4}{ }^{2-}$ の触媒定数 は非常に小さい $\left(k_{\mathrm{HA}} \doteqdot 0\right)$ ことが分かった。このように, $\mathrm{HPO}_{4}{ }^{2-}$ の触媒定数が非常に小さいことは, Brönsted の 触媒則によれば酸の触媒定数 $k_{\mathrm{a}}$ と酸解離定数 $K_{\mathrm{a}}$ の間に $k_{\mathrm{a}}=G_{\mathrm{a}} \cdot K_{\mathrm{a}}{ }^{\mathrm{a}}$ の関係式が成立し, 前述のよ5に $\mathrm{HPO}_{4}{ }^{2-}$ の酸解離定数が非常に小さいためと思われる。

以上述べたように， $k_{\mathrm{P}} \doteqdot 0, k_{\mathrm{HA}} \doteqdot 0$ であり，また Table 1 の No. 1 2, 5 6, 8〜9, 11 12 に打る $k$ の值はそれぞれの $\mathrm{pH}$ 值における $k^{\prime}$ よりもずっと大き いので, (2) 式において近似的に $k \doteqdot k_{\mathrm{A}^{-}}\left[\mathrm{A}^{-}\right]$とおくこ とができる.

\section{3 反応機構についての考察}

\subsection{1 従来の機構についての考察}

従来, 塩基触媒下における AGH のヒドロキシメチル 化は浦上ら ${ }^{2)}$, 佐藤ら 進行し, かつ (9) 式の反応が律速段階であると報告され ている.この機構はメラミン $(\mathrm{MH})^{9)}$ の際と同様であ る. $K_{2}, K_{3}$ はそれぞれ(8), (9) 式の平衡定数, $k_{3}, k_{4}$ は それぞれ (9), (10) 式の正反応の速度定数である.

$$
\begin{aligned}
& \mathrm{AGH}+\mathrm{A}^{-} \stackrel{\mathrm{K}_{2}}{\rightleftarrows} \mathrm{AG}^{-}+\mathrm{HA} \\
& \mathrm{AG}^{-}+\mathrm{HCHO} \stackrel{\mathrm{K}_{3}, k_{3}}{\rightleftarrows} \mathrm{AGCH}_{2} \mathrm{O}^{-}
\end{aligned}
$$

$$
\begin{gathered}
\text { (および } \left.\mathrm{AG}^{-}+\mathrm{CH}_{2}(\mathrm{OH})_{2} \rightleftarrows \mathrm{AGCH}_{2} \mathrm{O}^{-}+\mathrm{H}_{2} \mathrm{O}\right) \\
\mathrm{AGCH}_{2} \mathrm{O}^{-}+\mathrm{HA} \stackrel{k_{4}}{\rightleftarrows} \mathrm{AGCH}_{2} \mathrm{OH}+\mathrm{A}^{-} \quad \text { (10) }
\end{gathered}
$$

従来の考察に従い，第 1 に（9) 式の反応が律速段階 と考えると $R_{0}$ は (11) 式で示されるので, 特殊塩基触 媒反応である. しかし, 本報から一般塩基触媒反応であ る

$$
\left.\begin{array}{rl}
R_{0} & =k_{3}\left[\mathrm{AG}^{-}\right][\mathrm{HCHO}] \\
& =k_{3} K_{1} K_{2}\left[\mathrm{OH}^{-}\right][\mathrm{AGH}][\mathrm{HCHO}]
\end{array}\right\}
$$

ことが分かったので，(9) 式の反応が律速段階と考える ことは適当ではない。

第 2 に（8）式の反応が律速段階と考えると， $R_{0}$ は 
[F $]_{0}$ に無関係になるが，3.1に述べたよらに実験結果で は $R_{0}$ は $[\mathrm{F}]_{0}$ の 1 次に比例する. したがって，(8) 式の 反応が律速段階と考えることは不合理である.

第 3 に，(10) 式の反応が律速段階と仮定しょう．この 場合， $R_{0}$ は (12) 式で与えられるので, 一般塩基触媒反 応になる。

$$
\left.\begin{array}{rl}
R_{0} & =k_{4}\left[\mathrm{AGCH}_{2} \mathrm{O}^{-}\right][\mathrm{HA}] \\
& =k_{4} K_{2} K_{3}\left[\mathrm{~A}^{-}\right][\mathrm{AGH}][\mathrm{HCHO}]
\end{array}\right\}
$$

Jong $5^{10)}$ は塩基触媒下にお沙尿素のヒドロキシメ チル化に批いて(10)式に相当する反応を律速段階と報告 している.

しかし，(10) 式の反応は強塩基である $\mathrm{AGCH}_{2} \mathrm{O}^{-}$と 弱酸である HA のプロトン移動反応 (中和反応) なので 拡散律速反応と考えられ，律速段階にはなり得ないであ ろら(室温におけるプロトン移動の速度定数は約 $10^{10} \sim$ $10^{11} \mathrm{l} / \mathrm{mol} \mathrm{sec}{ }^{11)}$ といわれている).

以上述べたように，(8)，(9)，(10) 式の反応のうち，い ずれを律速段階と仮定しても適当でないので，従来考え られていた機構は適当でないであろう。

MHは液安溶媒中において，過㮃のカリウムアミドを 加えると共役塩基 $\left(\mathrm{M}^{-}\right)^{12}$ を生成するので, $\mathrm{AGH}$ も同 様に共役塩基 $\left(\mathrm{AG}^{-}\right)$を生成すると考えられる。しかし， 本報で用いた塩基触媒はカリウムアミドのよらな強力な 求核試薬でないので，本報で用いた塩基触媒だけでは AGH は共役塩基を生成しない，すなわち，(8) 式の反 応は進行しない結果であろう。

\section{3.2 本報からの考察}

この反応が一般塩基触媒反応なので, 主反応は(13), (14)式のように進行し，かつ，(14)式の反応は 3.3.1 に 述へたように速かで律速段階にはなり得ないので, 残り の(13)式の反応が律速段階と考えられる.

$$
\left.\underset{\mathrm{AGNH}}{2}+\mathrm{HCHO}+\mathrm{A}^{-} \rightleftarrows\left(\begin{array}{c}
\mathrm{H} \\
1 \\
\mathrm{AG}-\mathrm{N}_{1} \cdots \mathrm{CH}_{2} \mathrm{O} \\
\vdots \\
\mathrm{A}^{-} \cdots \mathrm{H}
\end{array}\right)\right\}
$$

$\mathrm{AGNHCH}_{2} \mathrm{O}^{-}+\mathrm{HA} \rightleftarrows \mathrm{AGNHCH}_{2} \mathrm{OH}+\mathrm{A}^{-}$

このように, $\mathrm{AGH}$ に対し, 求核試薬 $(\mathrm{N})$ である $\mathrm{A}^{-}$<smiles>C[14CH2]N</smiles>

(遷移状態)
および親電子試薬 (E) である F が協奏的に作用する， いわゆる協奏反応により， $\mathrm{AGH}$ のフミ/基水素はプロ トン移動が行われ，このプロトン移動が律速段階と考え られる.

塩基性に批るフセトンの臭素化によるモノブロムフ セトンの生成機構と比較すると，塩基によるアセトンの プロトン移動 (イオン化) が律速段階8),18) といわれてい るので, “基質 (AGH またはアセトン)のプロトン移動 が律速段階であることに関する限り”，類似性を示して いる.

付 記 終わりに本実験に熱心に協力された広川真理 孉に深謝する。本研究は第25回熱硬化性樹脂講演郡論会 (1975 年 10 月) で報告した。研究费の一部は文部省科学 研究費補助金によった．記して谢意を表する。

\section{文献}

1) 森本五良：日化誌，87，794 (1966).

2) 浦上 忠, 大岩正芳: 工化誌, 71, 591 (1968).

3) 佐藤謙二, 平根 優, 手塚哲治：第22回高分子 学会年次大会 (1973 年 6 月).

4) 佐藤薕二, 阿部芳首：高分子論集, 32, 687(1975).

5) 日本化学会編：“化学便臨” II, 丸善 (1971) p. 1314.

6) E. W. Washburn: "International Critical Table of Numerical Data", McGraw-Hill Book Company Inc., (1930) Vol. 7, p. 241.

7) H.S. Harned, R.A. Robinson: Trans. Faraday Soc., 36, 974 (1946).

8) R. P. Bell, P. Jones: J. Chem. Soc., 88, (1953).

9) M. Okano, Y. Ogata: J. Amer. Chem. Soc., 74, 5728 (1953).

10) J.I. De Jong, J. De Jonge: Rec. Trav. Chim.: 71, 643 (1952).

11) M. Eigen, J. Schön: Z. Elektrochem. 59, 483 (1955); M. Eigen: Angew. Chem., 75, 489 (1963).

12) E. Franklin: J. Amer. Chem. Soc., 44, 486 (1922).

13) H. M. Dawson, E. Spivey: J. Chem. Soc., 2180 (1930). 
Hydroxymethylation of Acetoguanamine with Formaldehyde in Phosphate Buffers*

Kenji SATO*1 and Yoshimoto ABE*1

*Studies on Melamine Resin. XIII.

*1 Department of Industrial and Engineering Chemistry, Science University of Tokyo (Yamazaki, Noda 278)

The early stage hydroxymethylation of acetoguanamine (AGH) with formaldehyde was studied at pH 11-12 by using disodium hydrogenphosphate-sodium hydroxide buffers. This reaction was subjected to the general base catalysis. Therefore, the main reaction is presumed to be the following (1) and (2), and (1) is rate-determining step, where $\mathrm{A}^{-}$and $\mathrm{HA}$ denote the base catalyst used and the conjugate acid, respectively.

$$
\begin{aligned}
& \mathrm{AGH}+\mathrm{HCHO}+\mathrm{A}^{-} \rightleftarrows \mathrm{AGCH}_{2} \mathrm{O}^{-}+\mathrm{HA} \\
& \mathrm{AGCH}_{2} \mathrm{O}^{-}+\mathrm{HA} \rightleftarrows \mathrm{AGCH}_{2} \mathrm{OH}+\mathrm{A}^{-}
\end{aligned}
$$

KEY WORDS Acetoguanamine / Formaldehyde / Hydroxymethylation / Base catalysis / Amino resin / Kinetics /

(Received December 15, 1975: Accepted February 5, 1976)

[Kobunshi Ronbunshu, 33(5), 257-261 (1976)] 